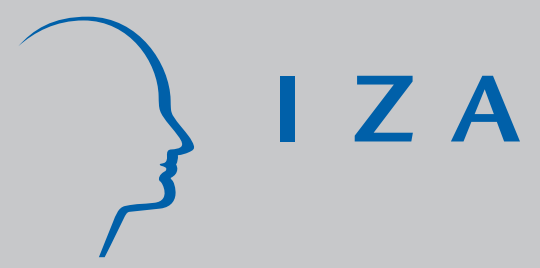

IZA DP No. 870

Analysis of the Determinants of Fertility Decline in the Czech Republic

Stephan Klasen

Andrey Launov

September 2003 


\title{
Analysis of the Determinants of Fertility Decline in the Czech Republic
}

\author{
Stephan Klasen \\ University of Munich \\ and IZA Bonn \\ Andrey Launov \\ University of Munich \\ and IZA Bonn
}

\section{Discussion Paper No. 870 \\ September 2003}

\author{
IZA \\ P.O. Box 7240 \\ D-53072 Bonn \\ Germany \\ Tel.: +49-228-3894-0 \\ Fax: +49-228-3894-210 \\ Email: iza@iza.org
}

This Discussion Paper is issued within the framework of IZA's research area Labor Markets in Transition Countries. Any opinions expressed here are those of the author(s) and not those of the institute. Research disseminated by IZA may include views on policy, but the institute itself takes no institutional policy positions.

The Institute for the Study of Labor (IZA) in Bonn is a local and virtual international research center and a place of communication between science, politics and business. IZA is an independent, nonprofit limited liability company (Gesellschaft mit beschränkter Haftung) supported by Deutsche Post World Net. The center is associated with the University of Bonn and offers a stimulating research environment through its research networks, research support, and visitors and doctoral programs. IZA engages in (i) original and internationally competitive research in all fields of labor economics, (ii) development of policy concepts, and (iii) dissemination of research results and concepts to the interested public. The current research program deals with (1) mobility and flexibility of labor, (2) internationalization of labor markets, (3) welfare state and labor market, (4) labor markets in transition countries, (5) the future of labor, (6) evaluation of labor market policies and projects and (7) general labor economics.

IZA Discussion Papers often represent preliminary work and are circulated to encourage discussion. Citation of such a paper should account for its provisional character. A revised version may be available on the IZA website (www.iza.org) or directly from the author. 
IZA Discussion Paper No. 870

September 2003

\section{ABSTRACT}

\section{Analysis of the Determinants of Fertility Decline in the Czech Republic}

In this paper we study the decline in total fertility rates in the Czech Republic during the transition process. To identify transition-specific features of this decline we use a multiperiod model of birth process and apply it to the family and fertility survey of 1998 . In a standard duration analysis setting the model allows for time-dependence of information sets, on which the decision about the next birth is made. It also enables to estimate probabilities of early exit from childbearing. In this work we find that the negative effect of transition on TFR is mostly translated through a sharply increased negative influence of higher education on fertility, and through the apparent lack of adequate childcare facilities.

JEL Classification: J00, J13

Keywords: $\quad$ fertility decline, transition countries, semiparametric estimation

Corresponding author:

Andrey Launov

Department of Economics

University of Munich

Ludwigstr. 28

80539 Munich

Germany

Tel.: +49 8921805604

Fax: +49 8921803954

Email: andrey.launov@Irz.uni-muenchen.de 


\section{Introduction}

Fertility decline in the transition countries of Central and Eastern Europe is a well known phenomenon in contemporary population economics. Fertility rates in most countries of Central and Eastern Europe have declined from close to replacement level (about 2) to levels far below that ensuring that populations in Eastern Europe will shrink considerably in coming decades. Increased mortality in some countries and rising emigration further accelerate this population decline. According to Sobotka (2001) it took just ten years for the post-Soviet countries as a group to move from the region with the highest fertility levels in Europe the one with the lowest fertility levels. A series of research papers attempts to classify this phenomenon and look into its possible sources. Among many others, there are comprehensive surveys by Billari and Kohler (2002) and Sobotka (2001), who present detailed studies of the evolution of a set of fertility indices and establish causal relationship between them and different socio-economic indicators. In particular, Billari and Kohler (2002) demonstrate that the trends towards lowest-low fertility in Central and Eastern European countries are accompanied with relatively early household independence and union formation. Moreover, the authors point out large diversity in evolution of fertility patterns in the European countries. They argue that despite the common problem of the total fertility decline, transition countries have their own distinct paths in this process and will exhibit little convergence with the rest of the Europe in the nearest future. Sobotka (2001) focuses the attention on the paths of the fertility decline in the transition countries. He identifies two different scenarios that depend on the success of the transition process itself. In relatively successful countries fertility decline is characterized with a strong postponement of the first birth, low first-birth rates, decline in teenage fertility rates etc., which implies a change to a new reproductive regime that is more similar to Western European countries. In less successful countries fertility decline occurs with rather slow postponement of the first birth, higher first birth rates and higher teenage fertility - the features of the old reproductive regime. Evolution of fertility patterns in the Czech Republic according to Sobotka (2001) proceeds along the first scenario. This also confirms findings of Billari and Kohler (2002), who additionally find low progression probability after the first child. The findings of Sobotka (2001) for the Czech Republic are in general supported by the survey of Mašková and Stašová (2000). The latter authors also provide the evidence of the changes in contraception use and the trends towards the end of the "abortion culture" of the pre-transition period. Finally, Burcin and Kučera (2000) perform a large-scale investigation of the influence of regional differences on fertility paths in the Czech Republic. They demonstrate that decline in total fertility is positively correlated with urban origins of women.

Reviewing this literature, one notices that the analytical methods, which are used to study the importance of given socio-economic variables in explaining fertility decline, include mainly descriptive statistics tools and comparisons. Here we would like to use a more formal econometric modelling techniques to address the same issue. To do so we formalize birth process as a probabilistic model, in which frequency and number of births depend on a set of individual characteristics. This will enable us to study which of these characteristics may significantly contribute to the decrease 
in the number of births and the lengthening of birth intervals. As fewer births and longer intervals between them are fair reflections of fertility decline, the variables that significantly contribute to those will be exactly the determinants of such a decline. The advantage of this approach is that it allows us to tell with greater degree of confidence whether a certain variable is important or not. In the present paper we make an attempt to study the phenomenon of fertility decline exactly through the estimation of the statistical model of birth process.

In view of the surveys mentioned above, we have to choose a model that is able to capture all the features of the fertility paths in the transition period. Namely, the model must be flexible in the analysis of waiting time between births, which will match the postponement, and in the analysis of the progression probabilities.

To the best of our knowledge three different types of models could be found in the literature dedicated to the topic. First of all there is a count data model, i.e. the model that specifies the number of born children as a random variable with all possible outcomes being counts. The model is constructed given certain assumptions on counts' probability distribution and their dependence on the set of covariates. Among applications of this class of models in population economics research one can notice papers of Famoye and Wang (1997), who estimate negative binomial model, and Covas and Santos Silva (2000), who work with modified hurdle extension of the preceding model. The second type is a so-called "sequential probability model" introduced by Barmby and Cigno (1990). It rather assumes that the birth process is a discrete time random variable, such that at each moment in time only one of two outcomes - 'birth' or 'no birth' is possible. The model is constructed given certain parameterization of the time-point probability. Eventually the third type is a multiperiod model of birth process developed by Heckman and Walker (1987), (1990, a-b). It is a discrete space continuous time model, which concentrates on modelling waiting times between adjacent births.

In the present work we use a multiperiod model of birth process to study the transition-specific features of the fertility decline. There are several reasons for this choice. Firstly, this setting is more flexible in modelling incomplete birth histories compared to the the standard count data model, which needs additional adjustments for that. Secondly, in the continuous time environment it becomes much easier to model the dependence of the next birth on the previous birth history and to introduce unobserved heterogeneity components. Finally, in the chosen framework we will be able to study the influence of explanatory variables on both timing of birth intervals and changes in the probability of exit from childbearing. None of this would have been possible with any of the other two models. Due to these advantages, we focus on the multiperiod model of birth process, even though the price to be paid is higher computational complexity.

The rest of the paper is organized as follows. The second section presents a more detailed discussion of the problem of declining fertility in the Czech Republic. This section also contains a description of the data used in the study. In the third section we describe a statistical model of the birth process and present its estimation methodology. Section four contains the discussion of estimation results and possible policy implications. Eventually the last, fifth, section summarizes main findings of the paper. 


\section{The Problem and the Data}

All transition countries underwent a massive fertility decline in the past decade. But the causes of these changes, however, seem to vary between regions and countries. Still there exist at least two facts that are uniformly true for all transition countries. The first is a decline in the total fertility rate and the second is a postponement of the first birth by newly created families. Since these phenomena apply to all the countries and not only to the Czech Republic, on which present study is focused, we will refer to them as as "stylized facts" in the contemporary evolution of fertility in Central and Eastern Europe.

As we have already mentioned, an indication of the first stylized fact for the case of the Czech Republic can be found in Billari and Kohler (2002) and Sobotka (2001) among many others. As to the postponement of births, Mašková and Stašová (2000) and Sobotka (2001) also presents convincing evidences of the phenomenon. Since the papers above clarify that both fertility decline and birth postponement are inherent features of the transition in the Czech Republic, in the present work we put ourselves a task of identifying the driving forces of these phenomena.

To deal with this task we use the data from the Family and Fertility Survey (FFS) of 1998. These data were collected in a cross-section survey of the families and couples and contain rich information on the timing of births and various characteristics of respondents. All our inference will be based on the estimation of the multiperiod model of birth process. Therefore we use such variables as the age of woman at the date of sampling, number of live births by woman and age of children at the date of sampling to restore birth histories of every woman from her entering the reproductive period until the end of the observation period or until exit from reproductive age. We assume that for each woman reproductive age begins at the time when she becomes sixteen years old. Furthermore, since one and the same covariate can have different effects on fertility decisions of a woman at different ages, we use the age variable to differentiate between three birth cohorts in the sample. The first cohort includes women from 16 to 26 , the second - from 27 to 35 and the third - women from 36 to 44 years old. We assume that the third cohort was largely affected by conditions prevailing in the pre-transition period, while the first cohort came of age after the transition process had begun. With this division we study evolution of birth histories for each cohort separately. We also calculate a total fertility rate (see Figure 1) and mean age at the first birth (Figure 2) during the 1988-97 period to demonstrate the stylized facts mentioned in the beginning of this section. To visualize both facts we additionally fit a polynomial curve to the TFR and data on mean age at the first birth. The Figures show, as expected, a drastically falling total fertility rate and a sharply rising mean age at first birth ${ }^{1}$.

The final bit of information on birth histories, important for the subsequent analysis, concerns censoring. As "censored" in this setting we refer to a time interval, for which the next birth is not observed due to the fact that the observation period is terminated while the woman in question is still in her fertile age and can potentially

\footnotetext{
${ }^{1}$ For richer summary statistics calculating age- and cohort-specific fertility rates refer to Billari and Kohler (2002) and tempo-adjusted Bongaarts-Feeney rates as Sobotka (2001)
} 
Figure 1: „, Total Fertility Rate in the Czech Republic in 1988-97 years“

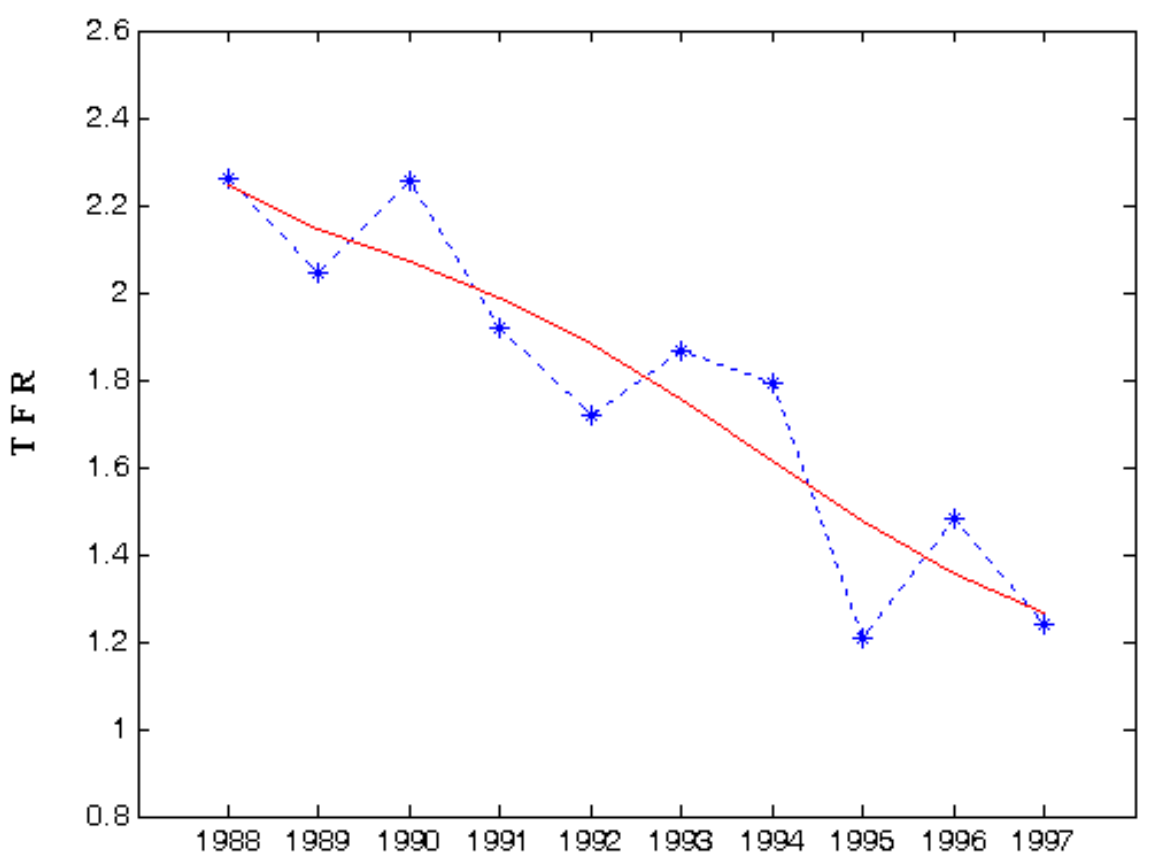

Figure 2: „, Mean Age of Women at First Birth in 1988-97 years “

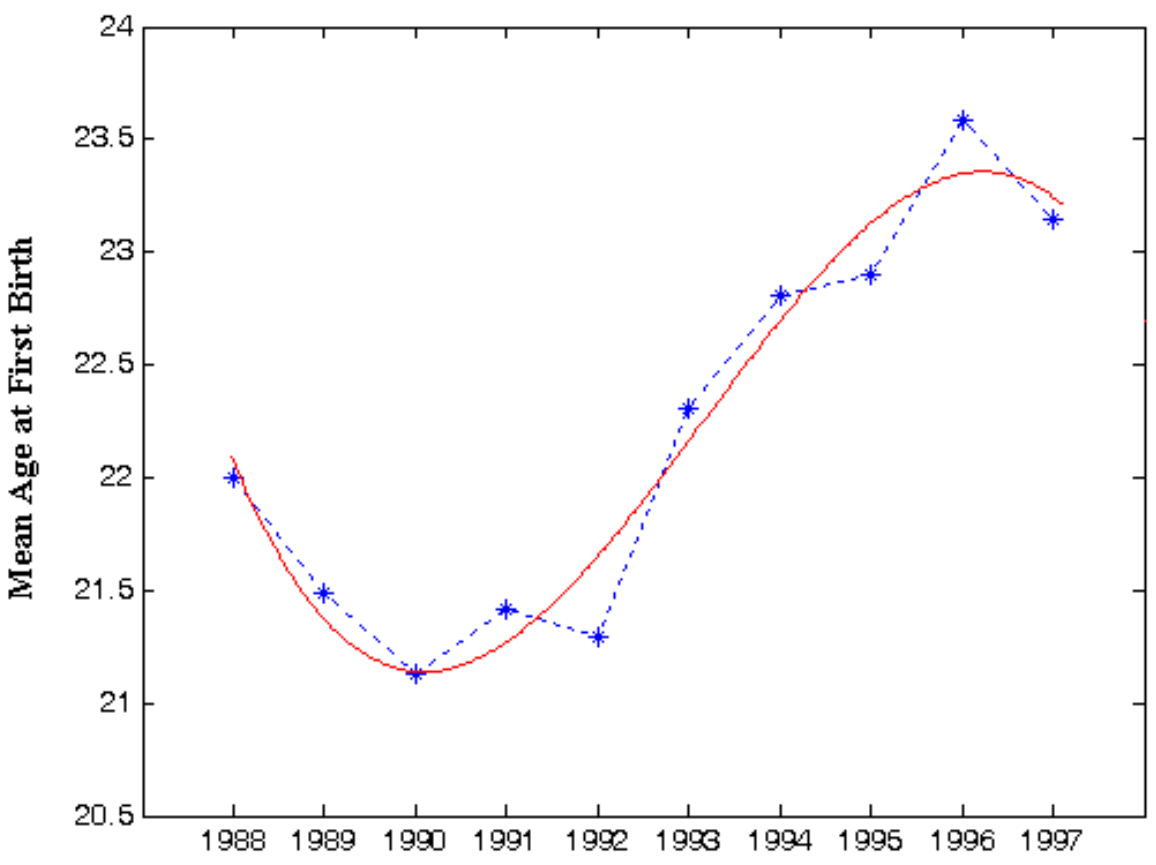


have children afterwards. From the data on the timing between births we can see that for the youngest cohort about $30 \%$ of all observations are censored between 0 and 1 births (i.e for about $30 \%$ of all women the first birth is not observed). Furthermore for more then $60 \%$ of all women in this cohort we can not observe the second birth and there is a negligible number of third (and more) births. For older cohorts, the effect of censoring is, naturally, less severe. Still the number of incomplete observations is high enough: $7 \%$ of all histories are censored between 0 and 1 and $28 \%$ are censored between 1 and 2 in the second birth cohort; $2 \%$ and $15 \%$ of observations respectively are incomplete in the third - the oldest cohort. The main message of these numbers is that the amount of censoring is too large to be neglected in any cohort and, secondly, does not allow making any inference on the number of births higher than two in the first birth cohort. Thus from the very start we are restricted to the analysis of only first and second birth. But since most of the fertility decline observed appears to be driven by having no children at all, postponement of the first birth and postponement and termination of child-bearing after the first birth, the available birth histories are sufficient to study the problem.

To explain the variation of the timing of births and decline in the number of births we use a set of variables that can be roughly divided on two groups, call them Socio-Economic and Belief Variables.

The first group contains socio-economic characteristics of a woman. Specifically, the data on the level of education, employment history, housing ownership data and the location indicator (rural/urban) for every female respondent are available. The education variable (edu) represents in this group an indicator of a level of acquired education ranging from " 1 " - 'first level' to "6" - 'third level, second stage, postgraduate', and we treat the variable as continuous. The employment variable (emp) is a summary of employment intensity (average hours of work) between any two adjacent births. It is constructed with the help of three components - the length of job spells between births $\left(T_{j}\right)$, the indicator of hours per week spent at each of these jobs $\left(I_{j}\right)$ and the whole length of waiting time between births $(T)$. So the variable measures a weighted average of weekly working hours between two adjacent births. Here weights are $T_{j} / T$ and the weighted variable is a discrete indicator $I_{j}$. $I_{j}$ is " 0 " when weekly hours were zero, "1" when weekly hours were less then 10 and so forth up to " 5 " if a woman worked more than 45 hours per week. Due to the discreteness of $I_{j}$ the resulting "employment" variable is a quasi-intensity, although it should represent the actual intensity fairly well. Ownership (own) data is a dummy variable, which is "1" if the dwelling is rented by a couple and "0" otherwise. Eventually the location indicator (urb) is a dummy variable that equals to one whenever the responding female spent the majority of her life before fifteen in an urban (more than 100,000 inhabitants) area.

We would generally expect that education and employment intensity both have a negative impact on the number and timing of children as they raise the opportunity cost of women's time. We would expect this to have an increasing effect after the onset of transition where the ability to combine work with children has been reduced. Ownership of a house might have a positive effect on child-bearing (as it represent a positive pure income effect) and urban residence might reduce the number of children as suggested by the literature discussed above. 
Unfortunately we miss at least one variable, which may have an influence on the timing of births. This is the income of either respondent or household. Since such a variable is absent in the original data set we have to make sure that the estimation procedure will be robust to omitted variables. Along with censoring described before, omitted income creates a methodological problem, which we consider in details in the next section.

The other group of variables- Belief Variables, contains variables that reflect respondents opinion on possible sources of fertility decline. The questions relating to the belief variables are not specifically asking about the respondent's own fertility history. But since women are asked about these beliefs after having being asked about their own fertility history, it is likely that they well reflect the women's subjective assessment about their own fertility history. We include them into the set of covariates since the information carried by these variables enables us to track the influence of the factors that manifest themselves through none of the quantitative variables listed above. The belief variables used in this study come from the section XI of FFS questionnaire that presents a list of circumstances that could have been important in explaining why "... women nowadays have fewer children than in previous generations". Every female-respondent was to assign each circumstance with degree of importance ranging from "unimportant" to "very important". On the grounds described below we select four such circumstances (i.e. reasons for fertility decline). For each of them we construct a dummy variable, which is "1" if a woman values the source as very important and "0" otherwise.

The FFS questionnaire offers a rich choice of reasons for the present fertility decline. At the same time we had to select only a limited number of the most appropriate variables. In the selection, we draw on the distinctions made by Sobotka (2001) between the "socialist greenhouse environment" and the dissolution of "socialist greenhouse" during the transition process. To present those briefly, it just suffices

to say that the author define five domains of social and private life and supplies each of them with a list of distinct features recorded at both socialist and transition periods. So the scheme makes it very easy to check for the changes, which transition brought about to social and private life. These domains are: '1.-Education', '2.-Career', '3.-Social security support and population policy', '4.-Private and family life, leisure, lifestyle and quality of life' and '5.-Reproduction and intimacy'. On the basis of this scheme we try to pick up the most important feature from each domain excluding education, information on which is already available, and end up with four essential belief variables for the fertility decline. They are:

- poor housing conditions $(p h c)$ - Social security and population policy domain

- insufficient child-care facilities (icf) - Social security and population policy domain

- growing desire among men and women for independence and personal advancement (dpa) - Private, family life and lifestyle domain; Career domain

- increased availability of contraception (iac) - Reproduction and intimacy domain 
Table 1: "Descriptive Statistics of the Covariates Used in the Study"

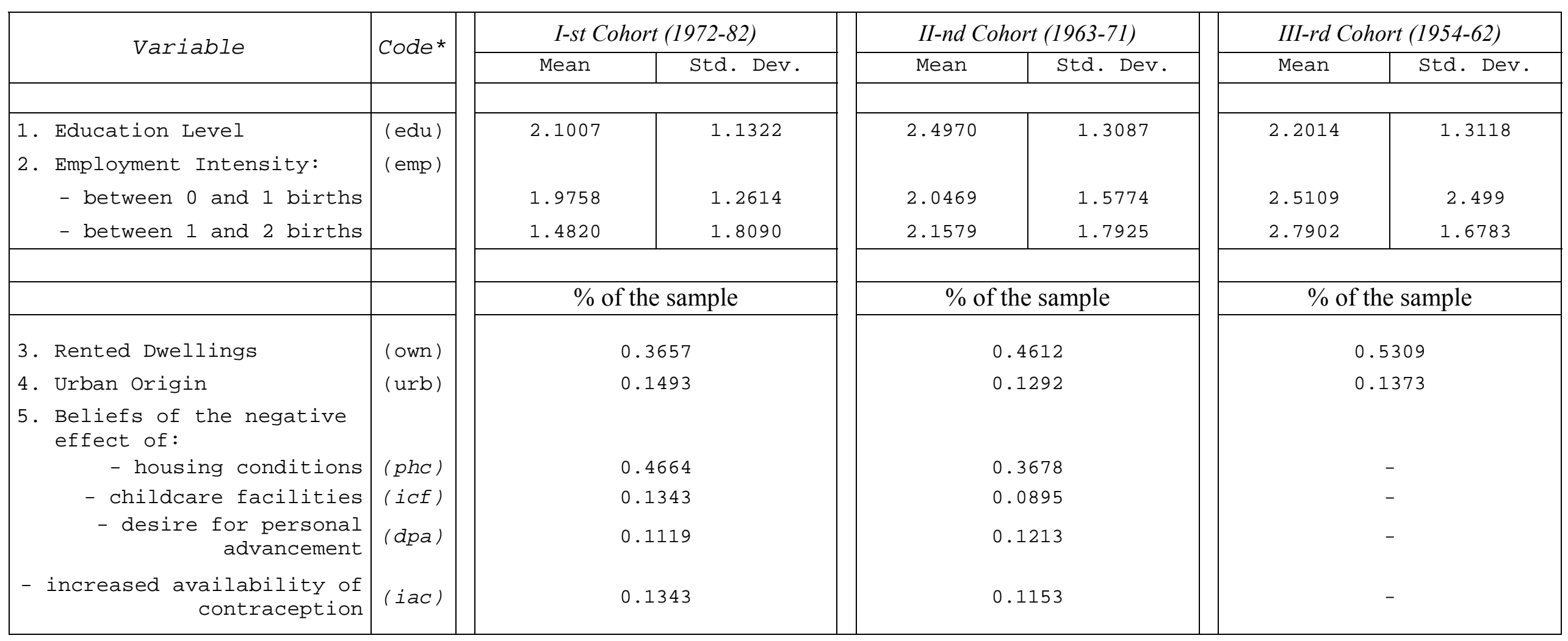

* Abbreviations listed in this column will be used when reporting the estimation results (see Tables A.1-A.3 in the Appendix) 
With the list above, it is possible to track the effect of various changes during transition (such as public policies favoring families with children), which is otherwise invisible in the socio-economic variables discussed above. This may justify their inclusion into the set of explanatory variables.

The last remark on the belief variables is that these are the opinions of people on the date of sampling so they play a role in making birth decisions only in the first birth cohort and, possibly, influence second-birth decision in the second birth cohort. Information carried by these variables is unrelated to the pre-transition period. Therefore, we exclude belief variables from the set of covariates, when estimating the model for the third birth cohort which had most of their children prior to the transition period.

We conclude this section with a table that reports on descriptive statistics of the independent variables used (see Table 1). We note that education levels increase between the oldest and the middle cohort. They then fall between the middle to the youngest, but this may partly be due to censoring problems as some women might still be in education at the time of the survey. ${ }^{2}$.

The employment intensity before the first birth and between births is falling considerably. This is likely to be related to increasing unemployment in the transition period, particularly for females (Klasen, 1994), as well as the growing incompatibility between child-rearing and full-time employment in the transition period, where childcare facilities have fallen away or become much more costly. Regarding the belief variables, surprisingly the housing conditions appear to be the most important stated reason for the decline in fertility, particularly for the youngest cohort. Lacking childcare facilities, desire for personal advancement, and increased contraception are also cited by a minority of respondents.

Table 1 also contains the codes of the independent variables, which are later used in reporting the estimation results.

\section{The Model and Estimation Techniques}

In the present section we describe in details the statistical model of the birth process and the problems associated with the consistent estimation of the parameters in the presence of unobserved heterogeneity and censoring. To formalize the birth process and describe the appropriate estimation procedure we will mainly follow Heckman and Walker (1990,a-b).

\subsection{Statistical Model of the Birth Process}

\section{General Description of Birth Process}

We suggest that the Birth Process is a continuous time stochastic process $\Im$ with finite set of possible realizations $\{0,1,2, \ldots, J\}$. The process starts at a certain cal-

\footnotetext{
${ }^{2}$ While this might potentially bias the results later on, we find that there are very few women who have children during their education (i.e. they have a child and then return to continue education), particularly in the post-transition era, so that any bias resulting from this would be small
} 
endar time $\tau(0)$, after which events occur at subsequent calendar times $\{\tau(j)\}_{j=1}^{J}$, spaced by time intervals of random length $\left\{t_{j}\right\}_{j=1}^{J}$. Let us view these intervals as realizations of random variables $\left\{T_{j}\right\}_{j=1}^{J}$. Then $T_{1}, T_{2}, \ldots, T_{J}$ are nothing else but waiting times between two adjacent births. Therefore we may suggest that for each of these random variables there exists a probability measure with a density function denoted by $g_{j}(t)$. By the nature of the waiting time, this measure is defined on the set $(0, \infty)$ for any $j$.

Next assume that at each point in time $\tau(j)+t_{j}$ there exists an information set based on which the decision of having or not having a(nother) child is made. We denote these conditioning sets as: $H\left(\tau(0)+t_{1}\right), H\left(\tau(1)+t_{2}\right), H\left(\tau(2)+t_{3}\right) \ldots$, where $\tau(j)$ is again the calendar time of event occurrence. We suggest that each of these conditioning sets contains at least variables $\left\{\mathbf{x}_{j}\right\}$ observable for both woman and analyst at each period. Moreover, the conditioning sets include a certain heterogeneity component, which is unobservable to the outside ${ }^{3}$. Let us treat the unobserved component as a random variable $\Theta$ with a set of all possible realizations $\{\underline{\Theta}: \Theta=\theta\}$ and probability measure $M(\theta), \operatorname{supp}(M(\theta))=\underline{\Theta}$. Then we may use the density of a time spell given the respective conditioning set

$$
g(t \mid H)=g(t \mid\{\{\mathbf{x}\}, \theta\})
$$

to find the marginal density of the time spell by integrating out the unobserved heterogeneity:

$$
g(t \mid \mathbf{x})=\int_{\underline{\Theta}} g(t \mid H) d M(\theta)=\int_{\underline{\Theta}} g(t \mid \mathbf{x}, \theta) m(\theta) d \theta
$$

The probability density $g(t \mid \mathbf{x})$ is central in the subsequent formulation of the likelihood function for the problem.

\section{Birth Process and the Dependence of Conditioning Sets}

The formalization of the birth process presented above overlooks, however, the fact that conditioning sets may be dependent on the prior birth history. In real life this is exactly the case when the probability of having the second child given the first one is not the same as the probability of having the first child. The differences may arise, for instance, due to acquired experience in childbearing, use of contraception or the fact that one has already reached or is close to reaching the desired family size. To introduce this feature into the model, Heckman and Walker (1990,a-b) suggest that unobserved heterogeneity (as seen from the researcher) can be split into two parts, the first of which is observable for woman after the occurrence of the event and the second is unobservable for both. Then contraception, childbearing experience and having reached the desired family size in the example above will fall into the first category. To the second category we can attribute, for instance, the natural fertility of the woman. In light of this, consider the marginal densities of two subsequent (for

\footnotetext{
${ }^{3}$ This is a necessary assumption, since we do not have income data and individuals are surely heterogeneous with respect to income. See Section 2 for the discussion.
} 
instance the first and second) spells

$$
\begin{aligned}
g\left(t \mid \mathbf{x}_{1}\right) & =\int_{\underline{\Theta}} g\left(t_{1} \mid \mathbf{x}_{1}, \theta\right) m(\theta) d \theta \\
g\left(t_{2} \mid \mathbf{x}_{2}, \mathbf{x}_{1}, t_{1}\right) & =\int_{\underline{\Theta}} g\left(t_{2} \mid \mathbf{x}_{2}, \mathbf{x}_{1}, t_{1}, \theta\right) m\left(\theta \mid \mathbf{x}_{1}, t_{1}\right) d \theta
\end{aligned}
$$

In this setting the marginal densities will not be the same even with time-invariant covariates, because $m(\theta)$ should not in general be equal to $m\left(\theta \mid \mathbf{x}_{1}, t_{1}\right)$. To formulate the appropriate second spell density we apply Bayes theorem and get

$$
m\left(\theta \mid \mathbf{x}_{1}, t_{1}\right)=\frac{g\left(\mathbf{x}_{1}, t_{1}, \theta\right)}{g\left(\mathbf{x}_{1}, t_{1}\right)}=\frac{g\left(t_{1} \mid \mathbf{x}_{1}, \theta\right) m(\theta)}{g\left(t_{1} \mid \mathbf{x}_{1}\right)}
$$

which implies that the marginal density of the second spell can be rewritten as:

$$
g\left(t_{2} \mid \mathbf{x}_{2}, \mathbf{x}_{1}, t_{1}\right)=\frac{1}{g\left(t_{1} \mid \mathbf{x}_{1}\right)} \int_{\underline{\Theta}} g\left(t_{2} \mid \mathbf{x}_{2}, \mathbf{x}_{1}, t_{1}, \theta\right) g\left(t_{1} \mid \mathbf{x}_{1}, \theta\right) m(\theta) d \theta
$$

It can be also shown that application of Bayesian updating demonstrated above generates for the larger number of births the following densities:

$$
g\left(t_{k} \mid\left\{\mathbf{x}_{j}\right\}_{j=1}^{K},\left\{t_{j}\right\}_{j=1}^{K-1}\right)=\frac{1}{\prod_{j=1}^{K-1} g\left(t_{j} \mid \mathbf{x}_{j}\right)} \int_{\underline{\Theta}}\left[\prod_{j=1}^{K} g\left(t_{j} \mid H\left(\tau(j-1)+t_{j}\right)\right)\right] m(\theta) d \theta
$$

$K \in\{1,2, \ldots, J\}$. Then, assuming conditional independence of $\left\{T_{j}\right\}_{j=1}^{K}$, the joint density that describes the entire birth history of a woman with $j$ realized births will become:

$$
f=\int_{\underline{\Theta}}\left[\prod_{j=1}^{K} g\left(t_{j} \mid H\left(\tau(j-1)+t_{j}\right)\right)\right] m(\theta) d \theta
$$

\section{Stopping of Childbearing}

In the formulation above we get the model which explains the influence of the set of covariates $\left\{\mathbf{x}_{j}\right\}_{j=1}^{K}$ on the length of waiting time between adjacent births taking into account unobserved heterogeneity of agents and the dependence of information sets on which agents base their birth decisions. In other words we will be able to see which variables exactly will contribute to either postponement or speeding up of births. At the same time, however, the problem of declining fertility is also a problem of increase in the amount of stopping after giving birth to $j$-th child. Therefore, to get a richer explanation of the phenomenon of fertility decline it is necessary to modify the model in such a way that will enable us to estimate the effects on both timing and stopping of births. This can be done by introduction of so-called "mover-stayer" probabilities, i.e. probabilities that given some number of already born children $K, K \in\{0,1,2, \ldots, J\}$ 
a woman will not have the next one. To bring these probabilities into the model we rewrite (1) in terms of survivor function, denoted by $S\left(t_{j} \mid H\left(\tau(j-1)+t_{j}\right)\right)$ :

$$
f=\int_{\underline{\Theta}}\left[\prod_{j=1}^{K} \frac{\partial}{\partial t}\left(-\ln S\left(t_{j} \mid H\left(\tau(j-1)+t_{j}\right)\right)\right) S\left(t_{j} \mid H\left(\tau(j-1)+t_{j}\right)\right)\right] m(\theta) d \theta
$$

Now assume that $p^{(k)}$-fraction of the current group of women will not continue childbearing after $l$-th birth, $l \in\{0,1, \ldots, K\}$. Since it is not known exactly whether a selected female will decide to stop, the probability of surviving the next time-spell $t_{l+1}$ for any female will be either the probability of stopping $p^{(l)}$ or the probability of surviving $t_{l+1}$ given that decision to keep on with childbearing is made. This will form new survivor function

$$
S^{*}\left(t_{l+1} \mid H\left(\tau(l)+t_{l+1}\right)\right)=p^{(l)}+\left(1-p^{(l)}\right) S\left(t_{l+1} \mid H\left(\tau(l)+t_{l+1}\right)\right)
$$

Substitution of (3) into (2) will then yield the joint density that accounts for the influence on timing of births and stopping the childbearing altogether.

This completes the formalization of the birth process.

\subsection{Estimation Methodology and Inference}

\section{The Likelihood}

In this paper we choose a semi-parametric approach to estimation of the parameters of interest. We suggest that, given unobserved heterogeneity, the waiting time between adjacent births is Weibull-distributed. At the same time we do not make any parametric assumptions about the distribution of the unobserved component. It is rather assumed that the distribution of the unobserved heterogeneity is discrete and its mass points and probability values attached to these points are estimated along with the structural parameters of the model. Let the distribution of the unobserved component have $I$ points of increase $\left\{\theta_{i}\right\}_{i=1}^{I}$ with corresponding probability values $\left\{\pi_{i}\right\}_{i=1}^{I}$. Then we can write down the Weibull density of a single time spell given covariates and the $i$-th heterogeneity point as

$$
g\left(t \mid \mathbf{x}, \theta_{i}\right)=\gamma\left(\exp \left\{\mathbf{x} \beta+\theta_{i}\right\}\right)^{\gamma} t^{\gamma-1} \exp \left\{-\left(\exp \left\{\mathbf{x} \beta+\theta_{i}\right\} t\right)^{\gamma}\right\}
$$

This density is used to form the survivor function as in (3):

$$
S^{*}\left(t_{l+1} \mid \mathbf{x}_{l+1}, \theta_{i}\right)=p^{(l)}+\left(1-p^{(l)}\right) \exp \left\{-\left(\exp \left\{\mathbf{x}_{l+1} \beta_{l+1}+\theta_{i}\right\} t_{l+1}\right)^{\gamma_{l}}\right\}
$$

Then using (2) and the survivor function above, the total contribution of $n$-th family with $K$ realized births to the likelihood can be formulated as

$$
\mathcal{L}_{n}=\sum_{i=1}^{I} \prod_{j=1}^{K}\left(1-p^{(j-1)}\right) \gamma_{j}\left(\exp \left\{\mathbf{x}_{j} \beta_{j}+\theta_{i}\right\}\right)^{\gamma_{j}} t_{j}^{\gamma_{j}-1} \exp \left\{-\left(\exp \left\{\mathbf{x}_{j} \beta_{j}+\theta_{i}\right\} t_{j}\right)^{\gamma_{j}}\right\} \pi_{i}
$$


At this point, a few words should be said about the estimation of mover-stayer probabilities. Firstly, since the probability is being estimated, it is necessary to restrict all its possible values to lie in $[0,1]$ interval. Secondly, it is necessary to introduce certain parameterizations to estimate the influence of the explanatory variables on stopping of childbearing. To achieve both, we follow Heckman and Walker (1987) who suggest for these purposes a logit parameterization of the form:

$$
p^{(j)}=\frac{1}{1+\exp \left\{-\mathbf{x}_{j} \omega_{j}\right\}}
$$

where the coefficients $\omega_{j}$ represent the effect of the regressors on the estimated probability. For the simpler non-parameterized version $\mathbf{x}_{j} \omega_{j}$ reduces to a constant common to everyone.

To complete the specification of the model we now turn to the issue of censoring. As it was mentioned in the description of the data, in our sample it is frequently the case that recorded the birth history concludes with incompletely observed spell of time after the last birth. This necessitates consideration of the probabilistic structure of censored time spells. The modification of the likelihood to tackle this problem is standard - to account for the censoring probability a density of waiting time after the last birth should be substituted with the respective survivor function. More formally, suppose that after $K$ births only $\bar{t}$ of total $t_{k+1}$ length of time until the next birth (or exit from fertility age) is observed. Then $n$-th family contribution to the likelihood (5) modifies to

$$
\begin{aligned}
\mathcal{L}_{n}^{c}=\sum_{i=1}^{I} & \prod_{j=1}^{K}\left[\left(1-p^{(j-1)}\right) \gamma_{j}\left(\exp \left\{\mathbf{x}_{j} \beta_{j}+\theta_{i}\right\}\right)^{\gamma_{j}} t_{j}^{\gamma_{j}-1} \exp \left\{-\left(\exp \left\{\mathbf{x}_{j} \beta_{j}+\theta_{i}\right\} t_{j}\right)^{\gamma_{j}}\right\}\right]^{I_{K}} \\
\times & {\left[p^{(K)}+\left(1-p^{(K)}\right) \exp \left\{-\left(\exp \left\{\mathbf{x}_{K+1} \beta_{K+1}+\theta_{i}\right\} \bar{t}\right)^{\gamma_{K+1}}\right\}\right] \pi_{i} }
\end{aligned}
$$

where $I_{K}=0$ in case $K=0$, and $I_{K}=1$ otherwise. With usual assumption of independence across individuals the total likelihood becomes:

$$
\mathcal{L}=\prod_{n=1}^{N_{u}} \mathcal{L}_{n} \prod_{n=1}^{N_{c}} \mathcal{L}_{n}^{c}
$$

where $N_{u}$ is the number of sampled women with uncensored fertility history and $N_{c}$ is the number of those with censored fertility history.

The specification of the problem is complete now. It is only left to note that in the present work parameters of interest in (8) are estimated using the EM algorithm. Originally the algorithm was proposed by Dempster, Laird and Rubin (1977). Apart from this article an insightful introduction to EM algorithm can be found in Lancaster (1990) and Heckman and Singer (1982). The latter reference provides also very good summary for its practical implementation ${ }^{4}$.

\footnotetext{
${ }^{4}$ Since the three sources above provide an extensive treatment of the algorithm we abstain from presenting a detailed description here.
} 


\section{Inference}

To conclude the methodological section let us say a few words about inference in the constructed model.

Firstly, consider the effect of the covariates on the hazard function. Taking the derivative of the hazard with respect to $\mathbf{x}$ we can see that the sign of the effect will always be equal to the sign of the estimated parameter. This means that a positive coefficient means that an increase in the covariate will lead to an increase in the hazard of having a child, and a decrease in the waiting time between births. Thus, we establish the reverse dependence between the length of the waiting time and the sign of the estimated coefficient.

In addition to that we can also compute the size of this effect. To do so consider expected value of a Weibull-distributed random variable given the exogenous covariates (see Lancaster (1990))

$$
E(T \mid \phi(\mathbf{x}))=\phi(\mathbf{x})^{-1} \Gamma\left(1+\gamma^{-1}\right)
$$

where in our case $\phi(\mathbf{x})=\exp \left\{\mathbf{x} \beta+\theta_{i}\right\}$. The presence of unobserved heterogeneity will modify this expectation to

$$
E(T \mid \mathbf{x}, \theta)=\sum_{i} \frac{p_{i}}{\exp \left\{\mathbf{x} \beta+\theta_{i}\right\}} \Gamma\left(1+\gamma^{-1}\right)
$$

Taking first order derivative of the above expression with respect to $\mathbf{x}$ we get the following marginal effects of covariates on the expected waiting time until the next birth

$$
\frac{\partial E(T \mid \mathbf{x}, \theta)}{\partial \mathbf{x}}=\sum_{i}-\frac{p_{i} \Gamma\left(1+\gamma^{-1}\right)}{\exp \left\{\mathbf{x} \beta+\theta_{i}\right\}} \beta
$$

As covariates enter $E(T \mid \mathbf{x}, \theta)$ non-linearly, marginal effects of the different levels of one and the same variable will not be the same. For example, an additional year of schooling for a person with university education will cause a change in waiting time different from that, caused by an additional year for a person with only secondary school education. Therefore, in order to ensure correct inference, marginal effects must be calculated for all possible levels of the explanatory variables.

Identical inference can be made about changes in quit probabilities. With parameterization as in (6) an increase in the value of the variable will cause an increase in probability of quitting after the realized birth, provided that the corresponding parameter is positive. The marginal effect of the covariates on the expected quit probabilities is analogously

$$
\frac{\partial E(P \mid \mathbf{x})}{\partial \mathbf{x}}=\frac{\exp \{-\mathbf{x} \beta\}}{(1+\exp \{-\mathbf{x} \beta\})^{2}} \beta
$$

\section{Estimation Results and Discussion}

This section contains the estimation results and their interpretation. As we have mentioned in our discussion of the data, only the first two births can sensibly 
be analyzed and are most important for the observed fertility decline. Therefore we estimate the model, which contains information only up to the third birth (or the end of observation period). Estimation is performed using an EM algorithm. Likelihood-maximizing mixtures are found by starting from the no-heterogeneity case and moving up in the number of heterogeneity points. The algorithm terminates when the likelihood cannot be improved anymore. For checking purpose Akaike and Schwarz information criteria were used. To ensure that achieved maximum is global ${ }^{5}$ for any given number of heterogeneity points the algorithm was repeated using a variety of different starting values. Estimation results are presented in Tables A.1-A.3 of the Appendix.

Already from the first glance at these results we can see the magnitude of the problem of fertility decline. Recall Figure 2, in which we demonstrated the increase in the postponement of the first birth. Now we are also able to add the evidence on the increase in quit probability after the first birth. From Tables A.1-A.3 it can be seen that during the socialist period the probability that a woman will stop childbearing after the first child is born was between 12\% (oldest cohort) and 17\% (middle cohort). In the youngest cohort, this probability more than doubles and to 39\% (see estimated "stayer" probability for the second child in Tables A1-A3). This difference is highly significant. Thus, the investigation of the effects of explanatory variables on the exit probability after the first birth acquires special importance. Along with postponement of the first and second birth this will be the focal point of the discussion that follows.

For the sake of completeness we need to say that the probabilities of having no children at all, which are also estimated from the model, will not be the focus of our attention, as it is difficult to separate biological effects (infertility) from socioeconomic effects of not wanting to have any children. ${ }^{6}$

In what follows we discuss the transition-specific influence of each variable on the postponement of births and early exit and consider its possible implications.

\subsection{The Determinants of Fertility Decline - Socio-Economic Determinants}

Education Level. The first interesting result here is a uniform negative influence of education on the timing of the first birth. As is plausible, higher education maps into a later first birth. This is exactly what we can see from the estimation results presented in Tables A.1-A.3 of the Appendix. For all birth cohorts an increase in education implies a longer waiting time until the first child is born. Furthermore, we see that the strength of the education effect increases from older cohort to younger cohort by roughly 27-29\% each, so that the total increase from the oldest to the youngest cohort is about $60 \%$. This observation can be formalized as a hypothesis of

\footnotetext{
${ }^{5} \ldots$ or at least the highest among all detected local maxima

${ }^{6}$ Also, the estimated stayer-probability reported in Tables A1-A3 should be treated with caution. Particularly for the youngest cohort, the estimated stayer probability of 0.00 suggests that all women will have children is not to be trusted as it is based on highly incomplete birth histories so that it is difficult to assess how many women will end up with no children. For the older cohorts, they are much more similar to the actual share of couples without children
} 
no-increase in the effect of education (i.e. equality of 'education' coefficients) across all the cohorts and tested by means of the standard Wald test. The results are presented in Table 2.

Table 2:" Test of No Increase in Negative Effect of Education on the Timing of the First Birth"

\begin{tabular}{cccc}
\hline \hline$H_{0}:$ & $\chi^{2}$ & DF & p-Value \\
\hline \hline & & & \\
$E D U_{I I}=E D U_{I I I}$ & 75.33525 & 1 & 0.00000 \\
$E D U_{I}=E D U_{I I}$ & 28.91179 & 1 & 0.00000 \\
\hline
\end{tabular}

These results clearly show that in the younger cohorts, the effect of education on postponing the first child is significantly larger, suggesting that during the transition process, the ability (and willingness) to combine education with early child-bearing has become much more difficult, leading to ever-greater education-induced postponements. Examining the marginal increments in waiting time as a result of education, which, as discussed above, cannot immediately be deduced from the coefficient due to the non-linearity of the model, provides further insights. These effects are plotted in Figure 3. First of all we notice that the marginal increase in waiting time increases nearly always with the level of education in all cohorts. However, in the oldest cohort which had most of their children during the socialist period, the curve is quite flat suggesting that higher education only slightly increases the waiting time between births. In the youngest cohort, which came of age during transition, the curve is much steeper suggesting that higher education has an increasingly stronger impact on the postponement of births. We see that for women with second level, second stage education, undergraduate and graduate education the decision to go ahead with schooling will postpone their first birth on $\frac{1}{2}$ to $1 \frac{1}{6}$ years more than it used to be in pre-transition times. In absolute terms this postponement will map into two to tree years. While right before the transition women with the same level of education who decide to continue their studies were at risk to have their first child only one and a half to two years later. So we conclude that socio-economic transition brought about much longer postponement of the first birth for females with medium and high level of education who wish to continue their studies. The longer postponement, however, does not apply to women with the lowest level of education. This finding is the first transition-specific feature of the evolution of fertility patterns in the Czech republic.

This finding is quite important for understanding the process of fertility decline and for thinking about possible public policy interventions. Clearly, the transition process has led to a situation where education and early child-bearing are becoming increasingly incompatible and this is an important factor accounting the tempo (postponement) component of the currently observed fertility decline. As female education levels are still increasing and continue to increase, it is expected that this will lead to further delays in child-bearing. In fact, this strong and rising influence of education on child-bearing is also prevalent in many Western European countries so that this tempo effect points towards a convergence of fertility trends in this regard (Sobotka, 2001). As far as policy is concerned, the only realistic option for stemming this trend 
Figure 3: „Marginal Effect of Additional Level of Education on the Timing of the First Birth“

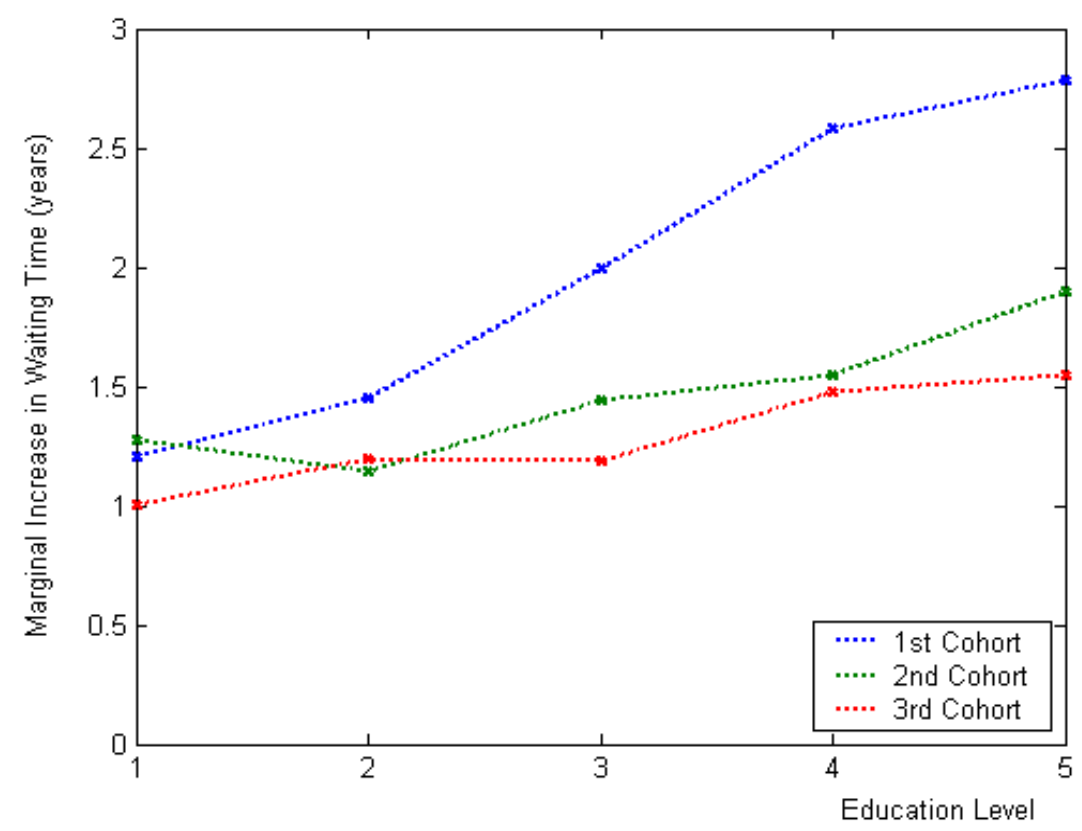

Figure 4: „,Marginal Effect of Additional Level of Education on the Quit after the First Birth during the Transition"

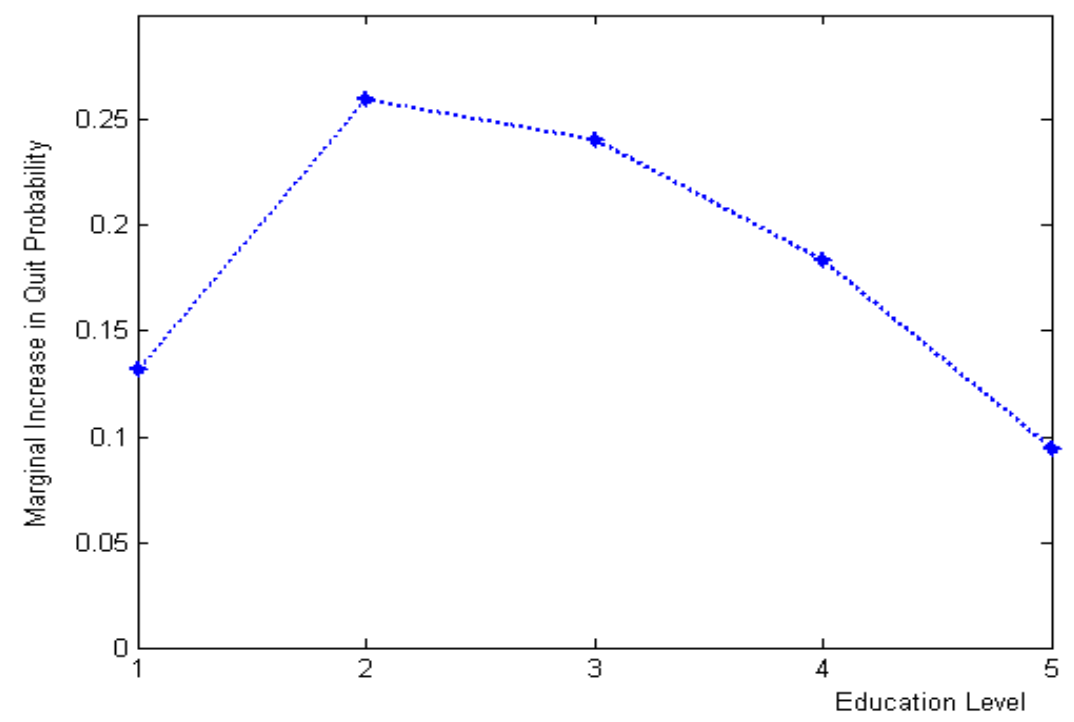


is to radically improve the ability of women to combine education with raising children. This would likely involve financial support, housing support,and support with affordable and flexible child-care.

It is also interesting to notice that socio-economic transition brought no large changes to the influence of education on the timing of the second birth. From Tables A.1-A.3 we see that 'education' coefficients are mostly non-signficant and not large in absolute size So the way in which education variable influences the postponement of births during the transition is fully consistent with the summary of Sobotka (2001) and others.

Now consider the influence of this variable on the exit from childbearing after the first birth. Tables A.1-A.3 show that the 'education' coefficients in the two older cohorts do not increase the quit probability after the first birth. In the youngest (post-transition) cohort however, education increases the quit probability significantly suggesting that transition has also reduced family sizes for educated women, thus explaining part of the quantum aspect of fertility decline during transition. Again, we can calculate marginal increase in quit probability at every education level (see Figure 4). An interesting pattern can be observed here. We see that in terms of the marginal increase in the quit probability a move up to a higher level of education has the largest marginal effect for females who currently master second level (2-3) and third level, first stage (4) education. In this case those who decide to acquire an additional stage will have 20-25\% higher chance to end up with a one-child family, than those who will cease to study. It is also interesting to notice that those who already have graduate education and wish to continue with postgraduate studies will have in fact a much lower marginal increase in quit probability than the women who stayed at the preceding stages. The same can be said about women with the lowest level of education. Thus we conclude that the switch from undergraduate to graduate level of female education has the largest marginal impact on the reduction of total fertility. We reiterate that the described inverted U-shape pattern in the marginal increase of quit probability due to education is a purely transition-specific effect, because corresponding education coefficients in the models for the older cohorts were not significantly different from zero. So we discover the second transition-specific feature of the evolution of total fertility in the Czech Republic nowadays.

Employment Intensity. The role of the next variable - female employment intensity, is not less important. As before one may expect that higher total hours cause later births and earlier quits. Again this is exactly what we get as a result. However, now the transition-specific patterns are much less obvious. Too keep the same order of analysis, let us start with the postponement of the first birth. From Tables A.1-A.3 we see that for all cohorts an additional unit of work intensity significantly increases waiting time until the first birth. Since all the coefficients are significant, we again apply sequential testing to recover the dynamics of the influence. From the results presented in Table 3 we see that there is a significant difference in the impact of employment intensity on the timing of the first birth between the oldest cohort and the two younger ones. Similar information is provided by the plot of marginal effects on the postponement of the first birth (see Figure 5). We see that 
Figure 5: „Marginal Effect of Employment Intensity on the Timing of the First Birth“

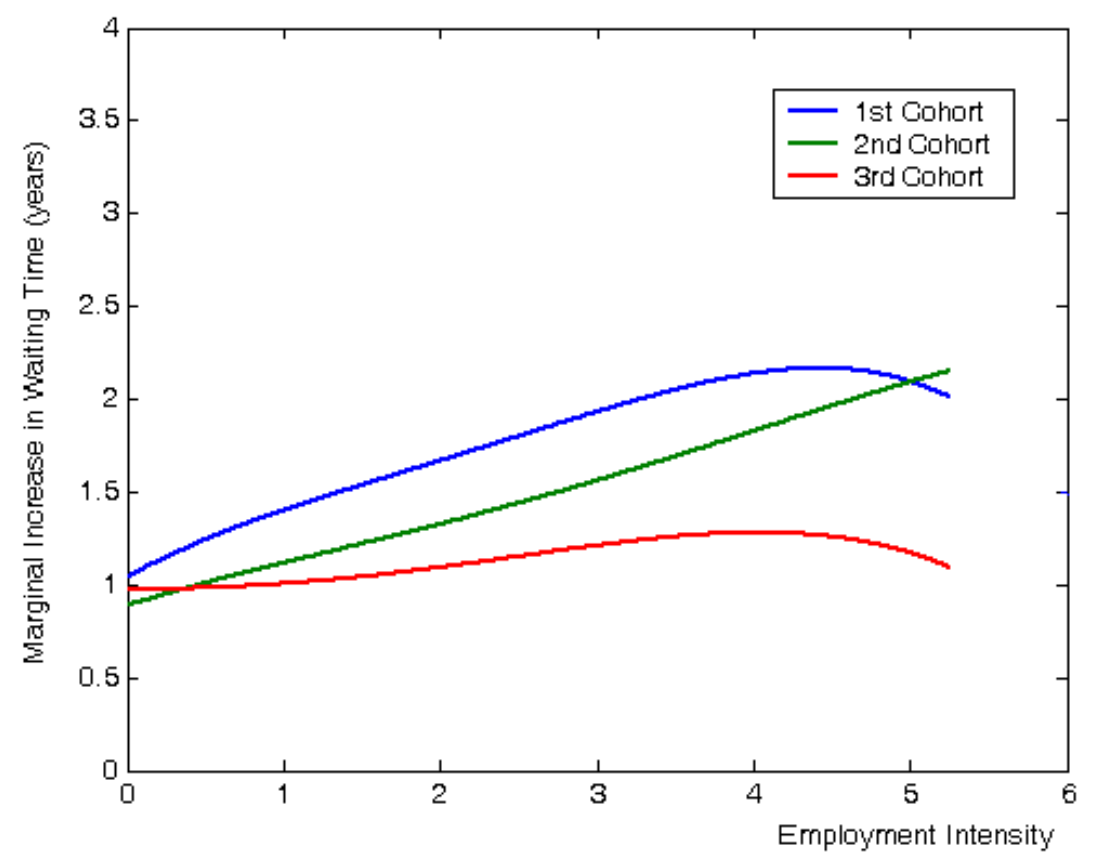

Figure 6: „,Marginal Effect of Employment Intensity on the Quit after the First Birth“

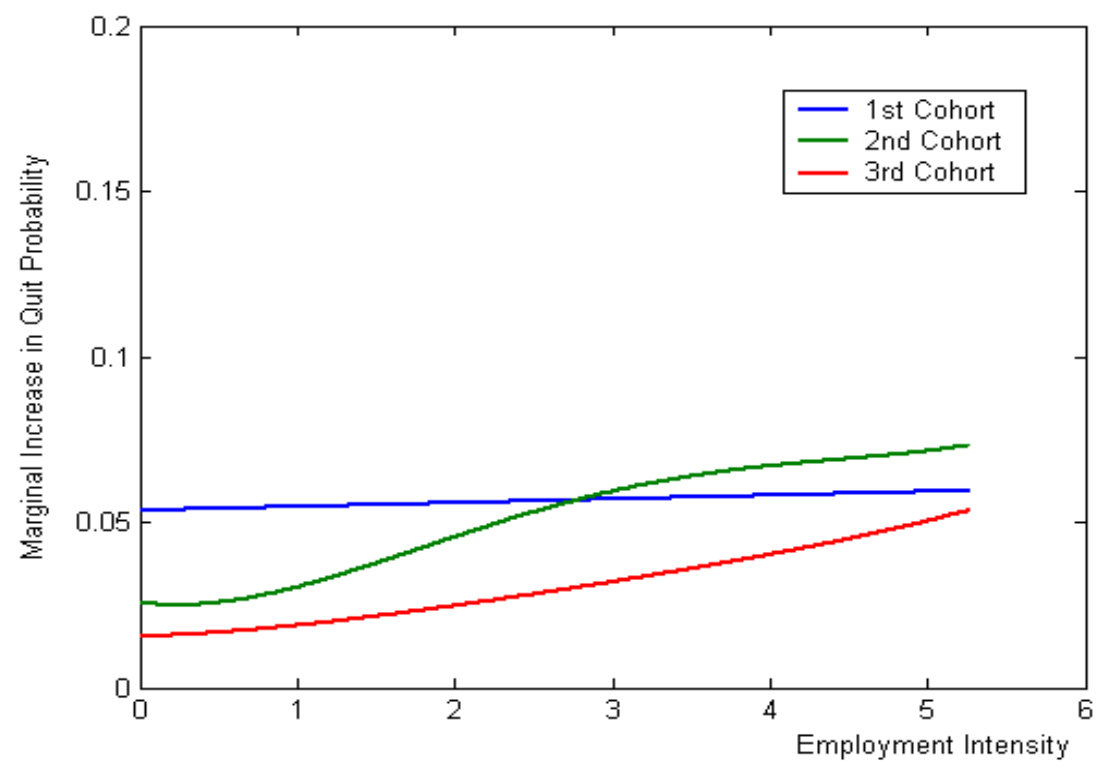


Table 3:" Test of No Increase in Negative Effect of Employment on the Timing of Births"

\begin{tabular}{cccc}
\hline \hline$H_{0}:$ & $\chi^{2}$ & DF & p-Value \\
\hline \hline & First Birth & & \\
& & & \\
$E M P_{I I}=E M P_{I I I}$ & 517.37702 & 1 & 0.00000 \\
$E M P_{I}=E M P_{I I}$ & 4.00544 & 1 & 0.04535 \\
\hline & Second Birth & & \\
& & & \\
$E M P_{I I}=E M P_{I I I}$ & 6.30511 & 1 & 0.01204 \\
$E M P_{I}=E M P_{I I}$ & 19.13688 & 1 & 0.00001 \\
\hline
\end{tabular}

by the end of the socialist era, the marginal increase in waiting time goes up with the level of employment intensity. Since the second cohort straddles the transition period, it is unclear to what extent they were already affected by transition in their fertility behavior. Given that their employment history mostly began after transition had begun, it is likely that transition influenced their reaction to employment on fertility decision. These results thus suggest that transition has lengthened the time period for to the first birth for women who are working full-time, suggesting that the compatibility between full-time employment and child-bearing has become increasingly difficult as transition progressed.

The influence of female employment intensity on the timing of the second birth is somewhat different. From the test results in Table 3 we can see that its effect was gradually dying out through the time and eventually became indistinguishable from zero. This actually implies that the transition period is in fact the most favorable a faster second birth. However, we find that the marginal increase in waiting time until the second birth due to the increase in employment intensity is just a matter of months. Generally the magnitude of the postponement was less than half a year and in the majority of cases it varied between one and three months. So, even though we observe the significant decaying trend of the harmful effect of employment intensity on the timing of the second birth, the effect itself is minimal and can be left out of consideration.

Let us proceed to the influence of variations in employment intensity on exiting from child-bearing after the first birth. First of all we see that this influence is significantly positive in all cohorts (see Tables A.1-A.3). Secondly it is constant throughout the time (see Table 4). So there are no real changes that happen during the transition period. From Figure 6 we also learn that a marginal increase in intensity will cause a roughly $5.5 \%$ increase in the probability. Probably the only difference between pre-transition and transition patterns of marginal effects is that in the transition period the effect of employment intensity becomes almost constant across intensity levels. So there are no people who will be relatively more and relatively less at risk to exit from childbearing earlier if their work intensity changes. The average risk is about the same as it was before. 
Table 4:" Test of No Increase in Negative Effect of Employment on Quitting from the Childbearing after the First Birth"

\begin{tabular}{cccc}
\hline \hline$H_{0}:$ & $\chi^{2}$ & DF & p-Value \\
\hline \hline & & & \\
$E M P_{I I}=E M P_{I I I}$ & 1.23689 & 1 & 0.266071 \\
$E M P_{I}=E M P_{I I}$ & 0.01077 & 1 & 0.917339 \\
\hline
\end{tabular}

Thus we conclude that the impact of transition on the effect of employment intensity on fertility is not major. Employment in transition is associated with a longer delay to the first birth, a slightly shorter one to the second, but a constant (positive) effect on quitting from child-bearing. While these results are suggestive, one should be careful in interpreting them as the employment decisions might be endogenous in the sense that women plan their employment and fertility decisions simultaneously. As the education variable is likely to be exogenous, we argue that the results on education gives a better reflection of the ability of women to combine education, work, and family than the results discussed above.

Ownership. The effect of ownership, is almost uniform. The results in the Tables A.1-A.3 indicate that it does not make any difference whether the dwelling is owned or rented. The only exception appears in the second cohort with a probability of not having children at all. For those with rented dwelling this probability is significantly higher and makes $4.8 \%$, which is $4 \%$ more than for those who own their apartment. This fact, however, cannot be directly related to the transition. So the conclusion is that ownership of the dwelling in nearly all circumstances does not appear to affect fertility decline during transition.

Urban origin. An indicator of whether a woman comes from urban (more than 100.000 inhabitants) area concludes the list of general qualities. The variable turns out to favor postponement of the first birth in socialist times. At the same time it does not have any effect on quits. So mothers' origin does not have disrupting influence on the completed fertility, but still can be the cause of declining observed fertility. Applying our sequential testing (see the results in Table 5) we affirm that during the socialist period the postponing effect was rather stable.

Table 5:"Test of No Increase in Negative Effect of Urban Origin on the Timing of the First Birth"

\begin{tabular}{cccc}
\hline \hline$H_{0}:$ & $\chi^{2}$ & DF & p-Value \\
\hline \hline$U R B_{I I}=U R B_{I I I}$ & 0.69039 & 1 & 0.406033 \\
\hline
\end{tabular}

There were no significant changes in its magnitude and on average those who come from urban area have their first birth one year later than those who come from elsewhere. During the transition period the influence on the timing of the first birth, however, weakens and becomes insignificant. 
It is also interesting to notice that urban origin was also contributing to the postponement of the second birth in the second cohort. This is already a borderline case, since about $70 \%$ of second births in the second cohort occurred already in the transition time. It becomes even more interesting to calculate the effect of it. It turns out that postponement of the second birth for urban females is again one year long. So we find that a switch to a new economic regime and start of the social changes forced one and the same people to postpone their second birth, which was not the case ever before. This finding also goes in line with Burcin and Kučera (2000), who find that among the total of six Czech cities with population of more than 100.000 inhabitants, three: Prague, Plzeñ and Brno enter the top five locations with the lowest TFR.

However, this pattern appears to hold only in the early phases of transition. If we look at the influence of urban origin on both births in the youngest cohort we realize that it has no explanatory power whatsoever. So we conclude, that even though the origin was an important transition-specific determinant at the start, its contribution to the postponement of births lately is not so strong.

\subsection{The Determinants of Fertility Decline - Beliefs}

We continue with interpretation of the influence of belief variables. Every belief variable is a dummy that a stated reason plays a very important role in contemporary fertility decline. Talking about beliefs we do not search for trends in socialistic times and their change in the transition time. The reason is that belief variables contain the information about the transition period only. That is why any influence of these is already a transition-specific feature of the evolution of fertility. On the same grounds we do not include these variables in the set of regressors used for the estimation of the model with the oldest cohort.

From the estimation results for the youngest cohort it turns out that no listed reason matters in the timing of the first birth. The only apparent exception is a statistical significance of the poor housing conditions. However, if we calculate the difference in waiting time between those who think that poor housing conditions are indeed the reason for the contemporary fertility decline and those who do not think so, we find that this difference is about three weeks only. So despite the variable being significant, its effect is too small to be of any interest. No other belief variables play any role in explaining the first birth postponement.

Partly this fact could be explained by the absence of relevant experience in childbearing among young couples. Still, it may partly come as a surprise. Looking at this result from another point of view, statistical insignificance of belief variables for the first birth decision reinforces the importance of education which alone ${ }^{7}$ appears to make an immense contribution to the increased postponement of having the first child, observed in the transition period.

For the second birth, though, beliefs do matter. From Table A.1 we see that there is a significantly positive relationship between waiting time until the second birth and insufficient childcare facilities. This means that women who consider childcare

\footnotetext{
${ }^{7}$ excluding the unobserved component
} 
facilities to be insufficient will try to have their second child faster. Evaluating the discrepancy in waiting time we realize that on average such women will have their second child one year earlier, than the others. At the first glance this implies a relatively high observed fertility. However, the influence of this belief on the total fertility will be precisely the opposite. The reason is that at the same time exactly those women who consider childcare facilities insufficient are much more likely to quit after the first birth and have no second child at all. This is inferred from the positive significant relationship between childcare belief variable and exit probability. To demonstrate how acute the effect of this belief is we again calculate quit probabilities. It turns out that women dissatisfied with the present childcare conditions will have $59 \%$ probability of not continuing the childbearing. While for the others this probability is only $35 \%$. So we see that those dissatisfied have a very high chance to end up with a one child family. Moreover the effect of this belief is so strong that those of them who eventually decide to have the second child will try to do it as soon as possible, which is indicated by the reduced postponement. The total effect of such behavior on the completed fertility must be negative, because postponement has only temporary importance and shifts observed fertility rates not affecting completed fertility. To the contrary, quitting drives down both observed and completed TFR. Thus we discover the third negative transition-specific property of the evolution of the Czech fertility.

Childcare facilities turn out to be the only contributor to the TFR decline. The rest of belief variables are insignificant. So we conclude that such factors as poor housing conditions, desire for personal advancement and independence and increased availability of contraception are not among the driving down forces of the fertility decline, invoked by socio-economic transition. What concerns the first two factors, their unimportance comes a bit as a surprise but may be due to the fact that these belief variables are fairly noisy indicators regarding the personal situation of the respondent. Regarding increased availability of contraception, we could have expected a causal relationship between increased availability of contraception and the timing (i.e. delay) of the first birth. This expectation grounds on the study of Mašková and Stašová (2000), who indeed find positive correlation between contraception expansion and currently observed fertility decline in the Czech Republic. But we cannot confirm this and the earlier result might be due to left-out variable bias.

\section{Summary and Conclusions}

Let us now summarize the main results of this study. As it was intended from the very beginning present work is focused on identifying the driving forces of the fertility decline in the Czech Republic during the transition period. Following the literature, we suggest that the observed fertility decline consists of two components, namely postponement of the next births and earlier quitting from childbearing (quantum effect). Moreover we argue that the tempo effect is temporary since it leaves a possibility that high enough number of children will be born eventually. Quitting to the contrary has a permanent effect.

In our analysis we identify three transition-specific phenomena that drive down total fertility rates. First of all, it is an increasing negative influence of education on 
the timing of the first birth. This means that in the transition period, with higher level of education women wait longer for the birth of the first child than it used to be in the socialist period. We also find that for women with undergraduate, graduate and postgraduate education this effect is especially strong. Secondly, there is a positive relationship between the level of education and the probability of exit from childbearing after the first child is born. This implies that during the transition people willing to increase their education level are much more likely to end up with a onechild family - the fact that could not be observed in the socialist era. The interesting feature of the relationship is that it has an inverted U-shape form. This means that the probability of stopping the childbearing after the first birth is the highest for women with undergraduate education, who decide to continue with their graduate studies. Eventually the third transition-specific phenomenon is a positive relationship between quits after the first birth and insufficient childcare facilities. Or, in other words, during socio-economic transition childcare facilities worsened sufficiently to make people abstain from having the second child.

So we conclude that the move from undergraduate to graduate education and insufficient childcare facilities are the sought channels, through which socio-economic transition negatively affects TFR in the Czech Republic nowadays. All other covartiates, either socio-economic variables or belief variables, turn out ether not to be significant at all or not change significantly during the transition process.

The policy implication from these findings appears to be clear. It appears that it has become increasingly difficult for educated women to combine work with family and efforts to address this short-coming are likely to be the most promising avenues for stemming this dramatic fertility decline in the Czech Republic, and likely in other transition economies.

\section{References}

[1] Barmby, T., Cigno, A., (1990), "A Sequential Probability Model of Fertility Patterns", Journal of Population Economics, 3, 31-51.

[2] Billari, F., Kohler, H.-P., (2002), "Patterns of Lowest-Low Fertility in Europe", Max Plank Institute for Demographic Research, Working Paper WP 2002-040.

[3] Burcin, B., Kučera, T., (2000), "Changes in Fertility and Mortality in the Czech Republic: An Attempt of Regional Demographic Analysis". In: Kučera T. et al. (eds). New Demographic Faces of Europe. Springer Verlag.

[4] Covas, F., Santos Silva, J., (2000), "A Modified Hurdle Model for Completed Fertility", Journal of Population Economics, 13, 173-188.

[5] Dempster, A., Laird, N., Rubin, D., (1977), "Maximum Likelihood from Incomplete Data via EM Algorithm", Journal of the Royal Statistical Society, Series B, 39, 1-38. 
[6] Famoye, F., Wang, W., (1997), "Modeling Household Fertility Decisions with Generalized Poisson Regression", Journal of Population Economics, 10, 273-283.

[7] Klasen, S., (1994), "Human Development and Women's Lives in a Restructured Eastern Block: Lessons from the Developing World". In: Schipka, A. and A. Taylor (eds). The Economic of Transformation. New York: Springer.

[8] Lancaster, T., (1990), "The Econometric Analysis of Transition Data", Cambridge University Press.

[9] MašKová, M., Stašová, L., (2000), "Population Development in the Czech Republic in the 1990s". In: Kučera T. et al. (eds). New Demographic Faces of Europe. Springer Verlag.

[10] Heckman, J., Singer, B., (1982), "The Identification Problem in Econometric Models of Longitudinal Data". In: W. Hildenbrand (ed). Advances in Econometrics. Cambridge University Press.

[11] Heckman, J., Walker, J., (1987), "Using Goodness of Fit and Other Criteria to Choose Among Competing Duration Models: A Case Study of Hutterite Data", Sociological Methodology, 17, 247-307.

[12] Heckman, J., Walker, J., (1990,a), "The Relationship between Wages and Income and the Timing and Spacing of Births: Evidence form Swedish Longitudinal Data", Econometrica, 58, 1411-1441.

[13] Heckman, J., Walker, J., (1990,b), "The Third Birth in Sweden", Journal of Population Economics, 3, 235-275.

[14] SовоткA, T., (2001), "Ten Years of Rapid Fertility Changes in European PostCommunist Countries: Evidence and Interpretation", University of Groningen, Working Paper. 
Table A.1:"Estimated Coefficients with Parameterized Mover-Stayer Probabilities: I-st Birth Cohort (1972-82)”

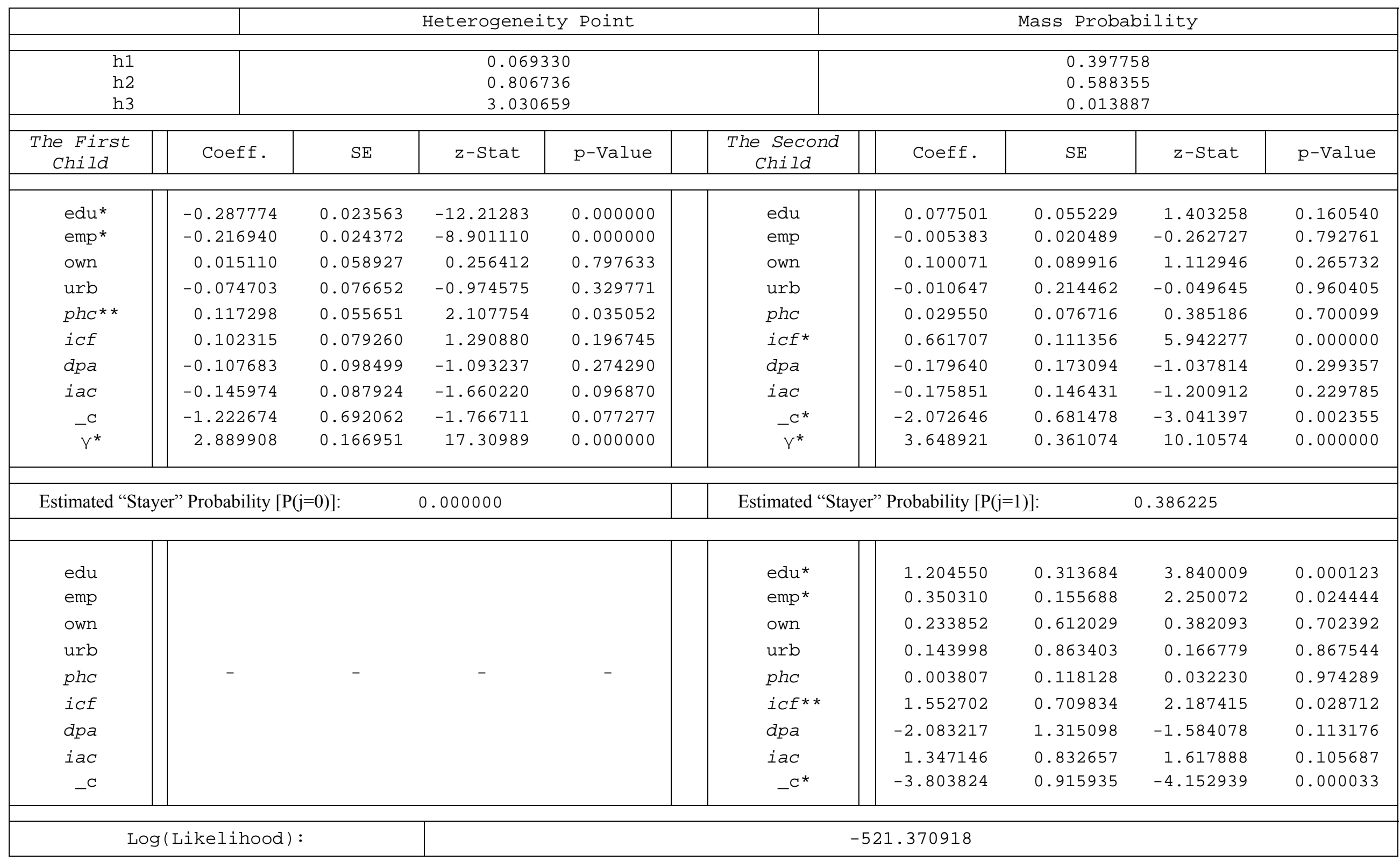

For convenience variables significant at 5\% level are marked with $\left(^{*}\right)$ and variables significant at $10 \%$ level are marked with $(* *)$. 
Table A.2:"Estimated Coefficients with Parameterized Mover-Stayer Probabilities: II-nd Birth Cohort (1963-71)"

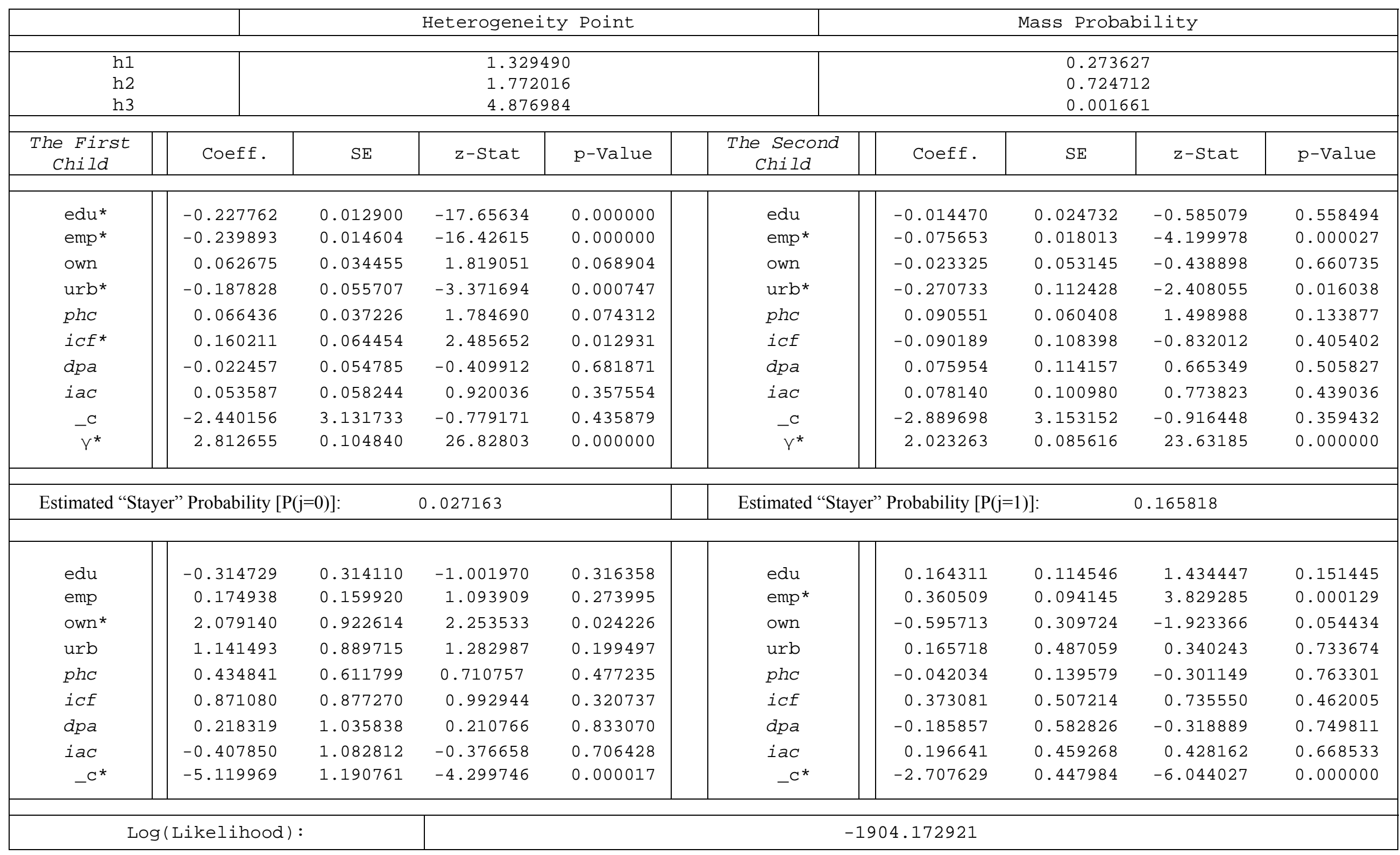


Table A.3:"Estimated Coefficients with Parameterized Mover-Stayer Probabilities: III-rd Birth Cohort (1954-62)"

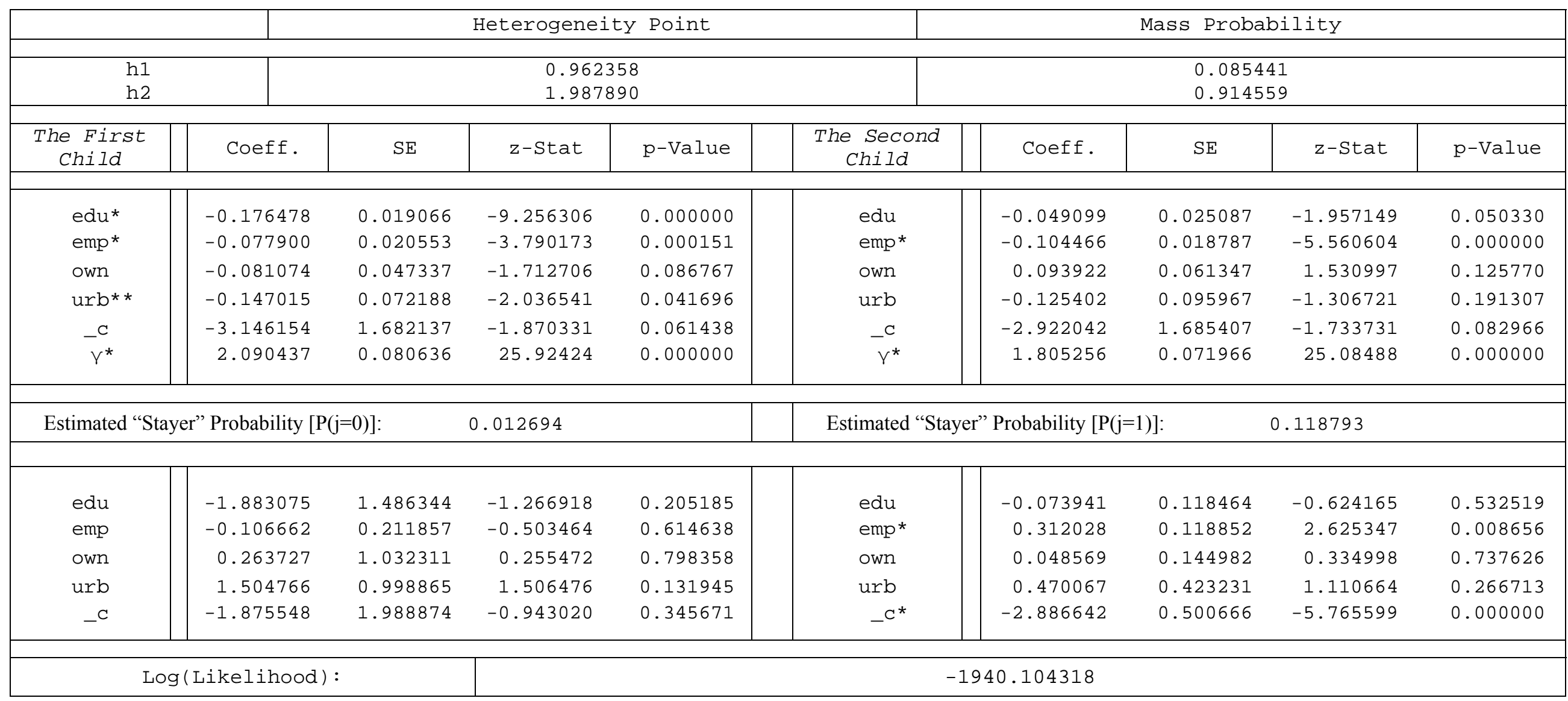




\section{IZA Discussion Papers}

\begin{tabular}{|c|c|c|c|c|}
\hline No. & Author(s) & Title & Area & Date \\
\hline 856 & D. Sliwka & $\begin{array}{l}\text { Management Incentives, Signaling Effects and } \\
\text { the Costs of Vertical Integration }\end{array}$ & 1 & $08 / 03$ \\
\hline 857 & $\begin{array}{l}\text { M. Francesconi } \\
\text { A. Muthoo }\end{array}$ & An Economic Model of Child Custody & 3 & $08 / 03$ \\
\hline 858 & C. U. Chiswick & $\begin{array}{l}\text { History of Historical Statistics of the United } \\
\text { States }\end{array}$ & 7 & $08 / 03$ \\
\hline 859 & R. Fahr & $\begin{array}{l}\text { Loafing or Learning? The Demand for Informal } \\
\text { Education }\end{array}$ & 5 & $08 / 03$ \\
\hline 860 & $\begin{array}{l}\text { J. Bonke } \\
\text { N. Datta Gupta } \\
\text { N. Smith }\end{array}$ & $\begin{array}{l}\text { Timing and Flexibility of Housework and Men } \\
\text { and Women's Wages }\end{array}$ & 5 & $08 / 03$ \\
\hline 861 & $\begin{array}{l}\text { Y. L'Horty } \\
\text { C. Rault }\end{array}$ & $\begin{array}{l}\text { Inflation, Minimum Wage and Other Wages: An } \\
\text { Econometric Study on French Macroeconomic } \\
\text { Data }\end{array}$ & 1 & $08 / 03$ \\
\hline 862 & $\begin{array}{l}\text { J. T. Addison } \\
\text { C. R. Belfield }\end{array}$ & Union Voice & 3 & $08 / 03$ \\
\hline 863 & C. U. Chiswick & $\begin{array}{l}\text { Immigrant Religious Adjustment: An Economic } \\
\text { Approach to Jewish Migrations }\end{array}$ & 1 & $08 / 03$ \\
\hline 864 & $\begin{array}{l}\text { D. Cobb-Clark } \\
\text { C. Ryan } \\
\text { R. Breunig }\end{array}$ & $\begin{array}{l}\text { A Couples-Based Approach to the Problem of } \\
\text { Workless Families }\end{array}$ & 6 & $08 / 03$ \\
\hline 865 & S. W. Polachek & $\begin{array}{l}\text { Mincer's Overtaking Point and the Lifecycle } \\
\text { Earnings Distribution }\end{array}$ & 5 & $08 / 03$ \\
\hline 866 & A. Constant & $\begin{array}{l}\text { Immigrant Adjustment in France and Impacts on } \\
\text { the Natives }\end{array}$ & 1 & $08 / 03$ \\
\hline 867 & $\begin{array}{l}\text { T. J. Dohmen } \\
\text { B. Kriechel } \\
\text { G. A. Pfann }\end{array}$ & $\begin{array}{l}\text { Monkey Bars and Ladders: The Importance of } \\
\text { Lateral and Vertical Job Mobility in Internal } \\
\text { Labor Market Careers }\end{array}$ & 1 & $08 / 03$ \\
\hline 868 & $\begin{array}{l}\text { P. Brañas Garza } \\
\text { S. Neuman }\end{array}$ & $\begin{array}{l}\text { Analyzing Religiosity Within an Economic } \\
\text { Framework: The Case of Spanish Catholics }\end{array}$ & 5 & $08 / 03$ \\
\hline 869 & $\begin{array}{l}\text { A. B. Krueger } \\
\text { A. Mas }\end{array}$ & $\begin{array}{l}\text { Strikes, Scabs and Tread Separations: Labor } \\
\text { Strife and the Production of Defective } \\
\text { Bridgestone/Firestone Tires }\end{array}$ & 3 & 09/03 \\
\hline 870 & $\begin{array}{l}\text { S. Klasen } \\
\text { A. Launov }\end{array}$ & $\begin{array}{l}\text { Analysis of the Determinants of Fertility Decline } \\
\text { in the Czech Republic }\end{array}$ & 4 & 09/03 \\
\hline
\end{tabular}

An updated list of IZA Discussion Papers is available on the center's homepage www.iza.org. 